ARCHIVO ESPAÑOL DE ARTE, LXXXIX, 354

ABRIL-JUNIO 2016, pp. 165-182

ISSN: 0004-0428, eISSN: 1988-8511

doi: 10.3989/aearte.2016.11

\title{
HACIA UNA ESTÉTICA DEL DÓNDE
}

\author{
Jorge Bernabeu Larena \\ Miguel Aguiló Alonso \\ Universidad Politécnica de Madrid \\ jorge.bernabeu@upm.es \\ maguilo@grupoacs.com
}

\begin{abstract}
La manera de construir propia de la ingeniería ha sido considerada por el arte a partir de su carácter técnico y a menudo referida a la dialéctica utilidad-belleza, tanto por los propios ingenieros como por los historiadores del arte. En un mundo donde todo es técnico, se introducen algunos conceptos para precisar ese carácter, como forma, tipo, proceso y ciertas pautas o metas específicas, relacionadas con lo ligero, lo estricto y lo superfluo. Se considera después la gran dimensión de esas obras, que supera la escala del hombre, y su relación con el territorio resumida en paisaje. A continuación se introduce la confrontación con lo natural y la aportación de lo sublime y lo pintoresco como vías de interpretación y valoración de lo construido. Con la introducción de los significados y del paisaje cultural se concluye la conveniencia de considerar la ingeniería desde una perspectiva fenomenológica, subrayando la importancia del 'donde' para entender sus peculiaridades.
\end{abstract}

Palabras clave: Arte; ingeniería; técnica; paisaje; fenomenología.

\section{TOWARD AN ESTHETIC OF 'WHERE'}

The building process of engineering works has been considered from the point of view of art for its technical character and often referred to the dialectic between utility and beauty, both by engineers and art historians. In a world where everything is technical, concepts such as shape, type, process and certain guidelines or specific goals related to lightness, strictness and superfluity are introduced. Then the large size of these works is taken into consideration, for they exceed the scale of man and his relationship with the territory, summarized as landscape. Here the confrontation with nature is introduced and the contribution of the sublime and picturesque as ways of interpreting and valuing the works. With the introduction of the meanings and concept of cultural landscape, the necessity to consider engineering from a phenomenological perspective is concluded, stressing the importance of 'where' to understand their peculiarities.

Key words: Art; engineering; technique; landscape; phenomenology.

\section{Una peculiar manera de construir}

Las acciones y productos del habitar propios de la ingeniería civil se otorgan de una manera característica, similar pero no idéntica a otras actividades del hombre. Responden a unas pocas necesidades básicas, como extenderse, ascender, regular, proteger etc., del ser humano como ha- 
bitante del mundo ${ }^{1}$. Con el tiempo, la atención continuada a esas necesidades ha generado una manera de actuar característica, muy vinculada a la naturaleza y con una escala referida al mundo, algo alérgica a lo superfluo, que usa el tipo como vínculo con la historia y se concreta en la esfera de lo público ${ }^{2}$.

Esa manera de construir puede ser creativa o rutinaria, dando lugar a obras de interés tecnológico, estético o artístico, o a simples copias. Pero incluso la mímesis puede llevar consigo el germen creativo y ser considerado desde el arte. Goethe distinguía entre ir miméticamente en pos de la naturaleza e imitar a la naturaleza misma en su acción creadora. Las artes, pensaba el poeta, "no imitan lo visible y tangible, sino el proceder oculto de la Naturaleza propiamente dicha, de modo que el arte habría de retornar a esa racionalidad que constituye a la naturaleza y según la cual actúa ésta"’3.

En esa acción de construir el sujeto actuante es el ingeniero, por más que la formulación de la necesidad ocurra en otros niveles de poder, más o menos representativos del grupo humano que la expresa. La satisfacción de la necesidad se consigue con el fruto de esa actuación, o conjunto continuado de acciones, que se entiende como la obra. El destinatario de la obra realizada es ese grupo que manifestó la necesidad o, con mayor generalidad, el público. Además, es el propio público quien la financia con peajes o impuestos.

Estas acciones de la ingeniería civil caracterizadas por una manera específica de actuar y referidas al establecimiento del hombre en el mundo completan las delimitaciones competenciales clásicas basadas en la exclusión o la adición. En el siglo XVIII, fue el ingeniero inglés John Smeaton quien primero utilizó el adjetivo civil para distinguirse del militar. Pocos años después, en Francia primero y luego en España, la actividad profesional se definió por adición de sus productos: Ingénieur de Ponts et Chaussées o Ingeniero de Caminos, Canales y Puertos.

En esa denominación es dominante su presencia permanente como ser-en el-mundo, de su actuación en la construcción del territorio, en cuanto supera la temporalidad de la extracción o la mera recolección. Por ello, en la última reestructuración de estudios, el correspondiente título de Grado en la escuela de Madrid (fundada en 1802) se ha llamado Ingeniero Civil y Territorial, reservando para el Master la denominación clásica de Ingeniero de Caminos, Canales y Puertos.

Esa adjetivación resalta la total vinculación de su quehacer con el territorio, claramente ausente en las ingenierías que realizan objetos, como la industrial, aeronáutica, naval o de telecomunicación, y tenida en cuenta solo parcialmente en cuanto al aprovechamiento de recursos en minería, agronomía o montes. En esa consideración, no interesa sólo la morfología del terreno, es imprescindible conocer los procesos naturales porque condicionan el dimensionamiento de las obras y pretenden la mínima alteración de lo existente.

Desde una perspectiva estética, la reflexión sobre estas actividades precisa superar todo dualismo y considerar al hombre como parte del sistema natural. Y ello conlleva una progresiva reconsideración de las anteriores pautas de reflexión, a veces también superadas por la propia evolución de la disciplina.

\section{El recurso a lo técnico: Forma, tipo y proceso}

Tradicionalmente, la consideración artística de las obras de ingeniería civil ha partido de su carácter técnico, como algo claramente distinto si no opuesto al arte. La dialéctica arte-técnica está inmersa en su valoración estética tanto a favor, como fundamento, o en contra como impedimento prin-

\footnotetext{
${ }^{1}$ Aguiló, 2013:14-16.

2 Aguiló, 2002:59.

${ }^{3}$ Goethe, J. W; 1821. Los años de peregrinaje de Wilhem Meister, VIII: 463
}

Arch. esp. arte, LXXXIX, 354, ABRIL-JUNIO 2016, 165-182 ISSN: 0004-0428, eISSN: 1988-8511, doi: 10.3989/aearte.2016.11 
cipal. Esa exigencia de resaltar la confrontación con la fuerza de la gravedad se manifiesta en los códigos del diseño estructural de la ingeniería como afán de ligereza y se amplía después a la idea de impacto ambiental en su consideración más territorial. Pero, en sentido amplio, manifiesta le exteriorización de una lucha como sustrato dialéctico de la obra, asunto de largo alcance estético ${ }^{4}$.

Desde el mundo de los ingenieros, esa dialéctica se ha centrado en el binomio utilidad-belleza, muy a menudo presentado como dicotomía (fig. 1). Entre las innumerables manifestaciones de su empleo como justificación o negación del carácter artístico de la ingeniería, valgan como muestra tres ingenieros de caminos españoles, académicos de Bellas Artes en las últimas décadas.

Para Carlos Fernández Casado, la argumentación de que la belleza reside en la utilidad es un ejercicio de 'pereza mental'. Pero no porque la utilidad sea desdeñable, sino por la riqueza de matices que contiene, y que son sistemáticamente reducidos e ignorados. Tras afirmar que "una iglesia puede ser más útil para el ser humano que un puente", separa muy bien la belleza de la utilidad: "Se ha hecho tópico que la belleza de una obra de ingeniería radica en su utilidad, aunque existen puentes horrorosos que no se hunden" (fig. 2). Para él, esa disyuntiva se puede superar: "Aunque la belleza no consiste en la utilidad, se coordina con ella".

Por su parte, José A. Fernández Ordóñez insiste en la dicotomía, ahora formulada como funcionalidad-belleza ${ }^{6}$. Una dicotomía que se disuelve en un obligado abrazo: "La belleza no puede apartarse, independizarse, de lo útil, de lo funcional, de lo necesario". Y apuntando la idea de lucha y algo más de precisión: "Arte y razón fueron siempre métodos alternativos, e incluso antagónicos,

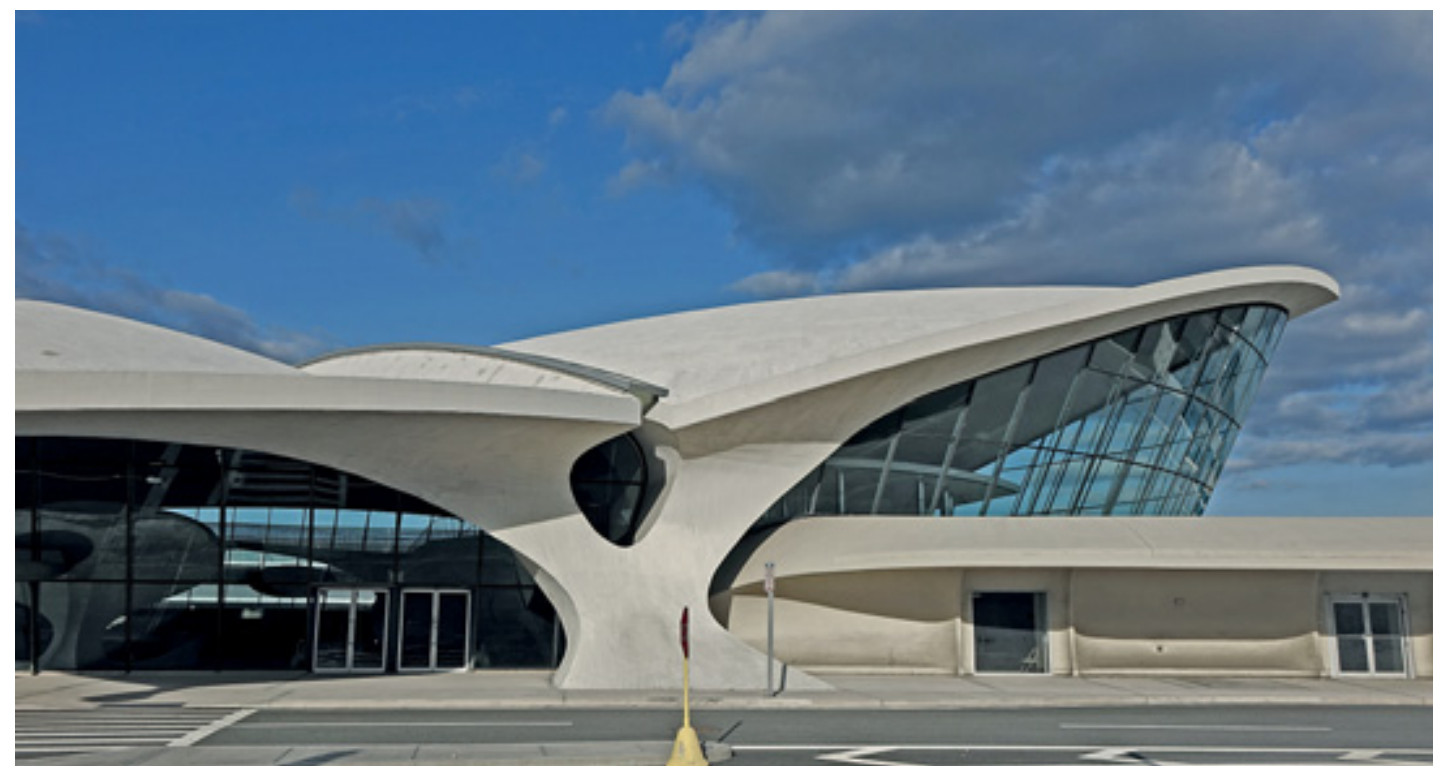

Fig. 1. Antigua terminal de la TWA, ahora sin uso, en aeropuerto JFK de Nueva York (Saarinen, 1962).

\footnotetext{
${ }^{4}$ Ya Schopenhauer, en La arquitectura desde el arte (1819:275), afirmaba: "La arquitectura considerada 'desde un punto de vista simplemente artístico', tiene la misión de expresar las representaciones más rudimentarias de la voluntad: peso, cohesión, resistencia y duración". Un poco más adelante, aclara: "Es la lucha entre pesantez y resistencia la que constituye por sí misma el interés estético de la buena arquitectura; hacer resaltar esta lucha de una manera compleja y perfectamente clara, tal es su tarea".

${ }^{5}$ Fernández Casado, 1976.

${ }^{6}$ Fernández Ordóñez, 1990.
}

Arch. esp. arte, LXXXIX, 354, ABRIL-JUNIO 2016, 165-182

ISSN: 0004-0428, eISSN: 1988-8511, doi: 10.3989/aearte.2016.11 


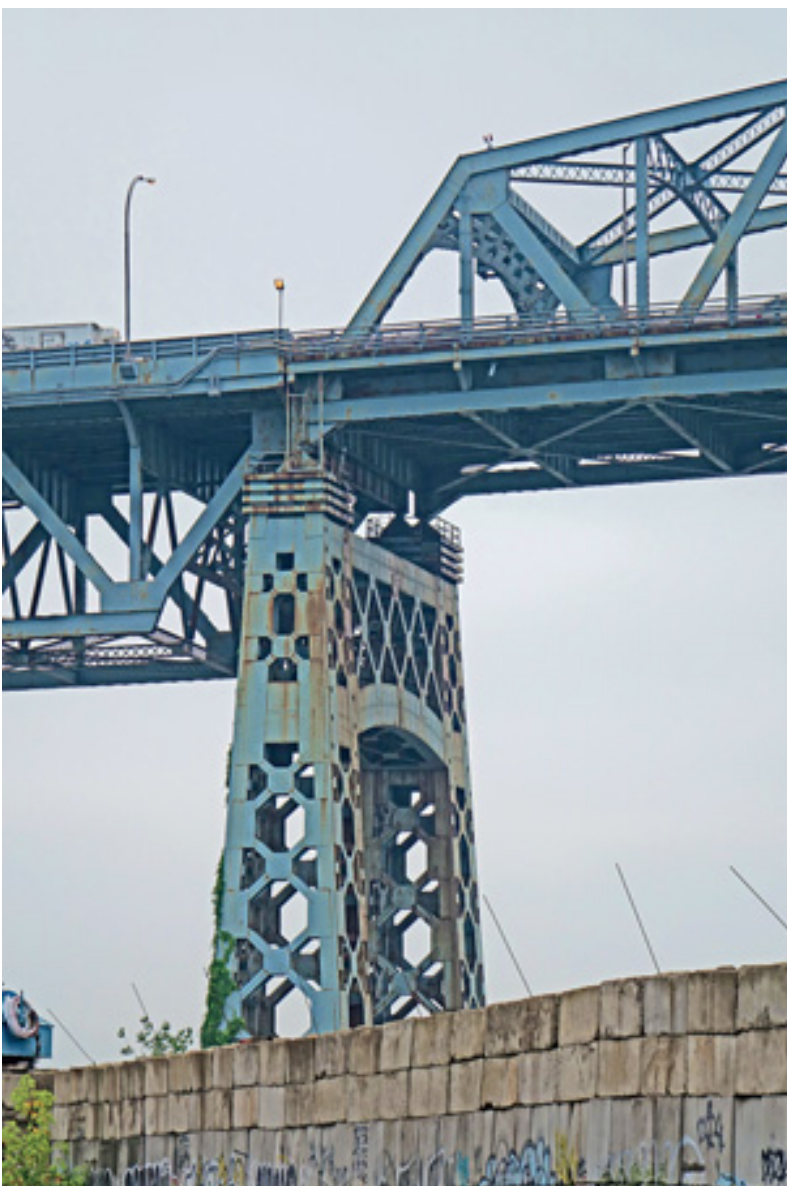

Fig. 2. Puente de Kosciuszko para la Brooklyn Queen Expressway sobre Newton Creek, enclave de máxima densidad de tráfico: feo e imprescindible.

de enfrentarse a la naturaleza, a la hora de construir. Fundirlos en sus obras es el destino último del ingeniero"”.

Más recientemente, Javier Manterola deja de lado la utilidad y se centra en lo resistente. Su conexión con la belleza se hace patente al establecer la manera de resistir como fundamento de la forma adoptada: "Para los ingenieros... los buenos diseños no eran una interpretación formal del hecho resistente sino que debían ser el descubrimiento de su esencia. En el fondo, lo resistente tenía la exigencia de ser desvelado formalmente"

\section{Forma, tipo y proceso}

Lo construido nace de la interacción cambiante del lugar, el tipo y la forma. El lugar conecta con el mundo donde habitamos, el tipo organiza la experiencia tecnológica y la forma resume la expresión creativa del diseñador. Lo técnico se manifiesta fundamentalmente a través del tipo y el proceso que, como parte de la esencia de la obra, son comunicados por medio de la forma ${ }^{9}$ (fig. 3 ).

Las cosas construidas son múltiples y diversas, y de su examen comparativo se deriva el tipo, como núcleo de sentido compartido entre muchas de ellas. Estas cosas se basan en las construidas anteriormente y permiten una acumulación de experiencia que, como abstracción deducida de sus similitudes y diferencias, se recoge en los tipos ${ }^{10}$.

Al hacer frente a las dificultades del lugar con las innovaciones tecnológicas en distintos momentos históricos, esos tipos primarios se han ido cargando de significados ligados a la época en que se establecieron como solución de referencia. El arco resuena como romano, la celosía recuerda la primera industrialización inglesa y el cable colgante se vincula al desarrollismo americano. Esos significados adheridos a los tipos estructurales difuminan la función resistente y la diluyen en el protagonismo simbólico de la forma.

La racionalidad resistente de estos tipos estructurales no es escudo suficiente para la posterior adherencia de profundos significados. La carga semántica aportada por el uso histórico del tipo

\footnotetext{
${ }^{7}$ Fernández Ordóñez, 1988:34 y 50.

${ }^{8}$ Manterola, 2007: 28.

9 Aguiló, 2013:26.

${ }^{10}$ Aguiló, 2008:46.
} 
reduce su valor explicativo. La pertenencia al tipo suele dar entrada a un primer esquema de valoración de la forma, pero se consume en las adherencias estilísticas de la propia obra. Por otra parte, la aparición de nuevos métodos de cálculo, de alcance universal y válidos para todos los tipos, ha desdibujado el valor diferencial del tipo en favor de la potencia numérica del algoritmo. El papel de las reglas de buena práctica contenidos en los tipos deja paso a la posibilidad de comprobación inmediata de cualquier hipótesis mediante el cálculo electrónico. Y, como consecuencia directa de la independencia de los esquemas consagrados, introduce más grados de libertad en el diseño.

En la historia de lo construido todavía subsiste la creencia en unas formas de la ingeniería surgidas casi automáticamente del cálculo y la técnica. Basta asomarse al exterior, a cuanto se hace ahora en el mundo, para ver justo lo contrario, es decir, cómo similares problemas tecnológicos son resueltos de muy diferentes maneras, tanto espléndidas como horrorosas. Pero son muchos los arquitectos e ingenieros que persisten en negar toda creatividad en el diseño ingenieril.

Por un lado, estrechos intereses y la defensa de competencias profesionales pretenden acaparar todo lo relacionado con la definición de la forma. Por otro, hay cierta renuencia a admitir la total libertad del diseñador en la forma de un puente, una presa o una carretera.

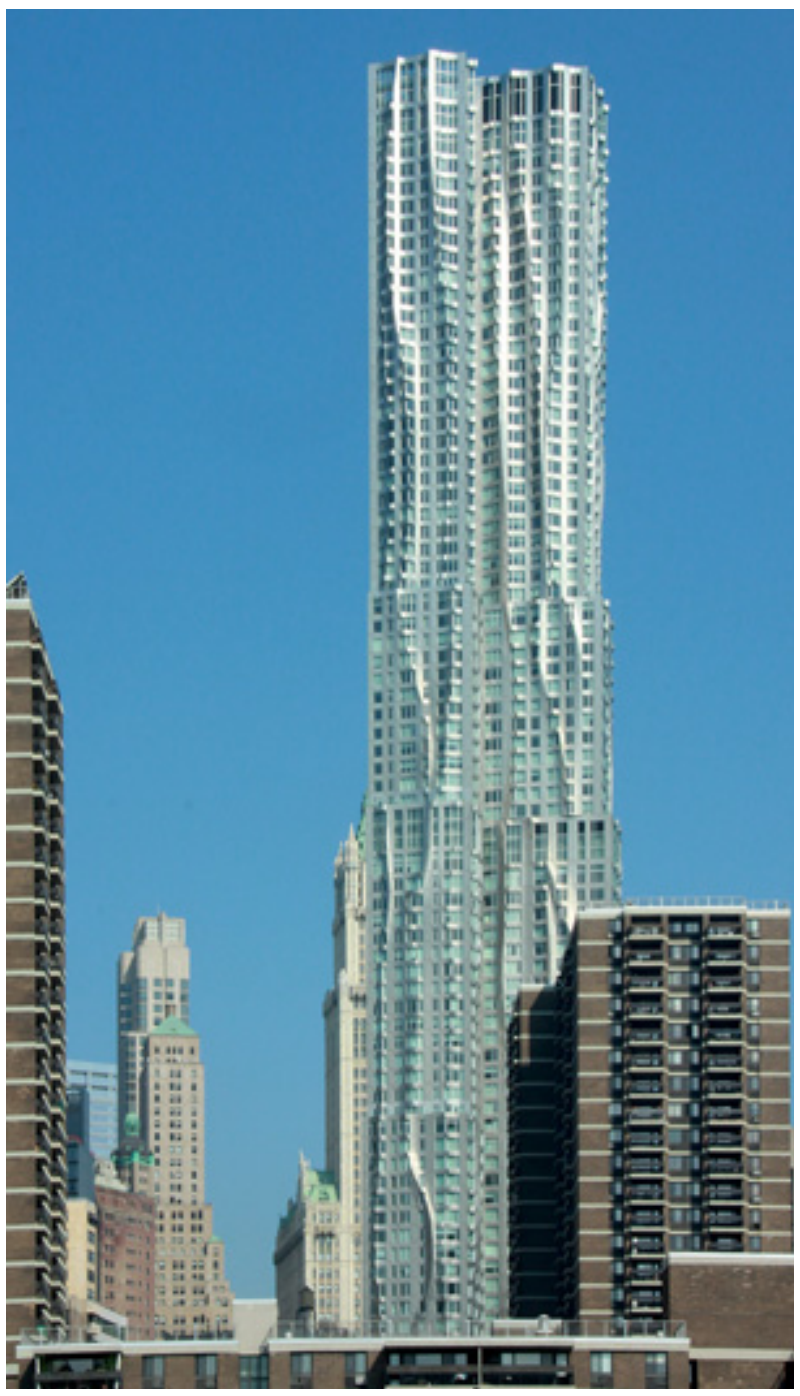

Fig. 3. Torre en Spruce St., Manhattan (Frank Ghery, 2011). Quizás para rehuir su responsabilidad o por pura 'pereza' (como decía Fernández Casado), muchos ingenieros siguen defendiendo cierto automatismo de las soluciones. Pero con sus aciertos y fracasos, las obras de los grandes diseñadores no dejan lugar a dudas de su impronta, del sello de su peculiar tectónica presente en todas sus obras ${ }^{11}$.

Como afirma el principio clásico, Forma dat esse rei (La forma da el ser a la cosa) y durante mucho tiempo, la forma ha sido el referente indiscutible de cualquier apreciación artística. El propio Adorno afirma que "Las posibilidades del arte son las mismas que las de la forma y no más", cerrando en principio cualquier otra fuente de interés. Pero avanza una interpretación de la integración de la función y la técnica en la propia forma cuando remacha: "Sustancialmente, la forma constituye algo unitario cuando no violenta lo conformado sino que se eleva a partir de ello.

\footnotetext{
11 Aguiló, 2008:76.
}

Arch. esp. arte, LXXXIX, 354, ABRIL-JUNIO 2016, 165-182

ISSN: 0004-0428, eISSN: 1988-8511, doi: 10.3989/aearte.2016.11 
Y lo conformado, el contenido, no son objetos externos a la forma, sino los impulsos miméticos a los que el contenido arrastra hacia ese mundo de imágenes que es la forma"12.

Esa formulación permite acercar posiciones pues, admitiendo su autonomía y el protagonismo de su creador, la forma estaría obligada a coexistir de una manera unitaria con unos contenidos capaces de 'arrastrarla'. Sería entonces el acierto del diseñador de donde surgiría la síntesis o conciliación de la dialéctica forma-contenido, eliminando toda referencia a cualquier automatismo o canon externo único y eterno.

Por otra parte, las nuevas posibilidades de representación, cálculo y diseño ofrecidas por los ordenadores permiten tal variedad de diseños para un mismo problema, como para reafirmar la amplia libertad del diseñador para fijar la forma. El refugio en pretendidas verdades objetivas, más o menos automáticamente surgidas de la técnica, debe hacer sitio a la total aceptación del protagonismo de la forma y, como consecuencia, del papel de la crítica como única fuente de valoración artística.

\section{Lo ligero, lo estricto y lo superfluo}

Pero la presencia de la tradición tecnológica en la valoración crítica sigue siendo significativa. Hay una serie de cuestiones básicas, tanto en la ingeniería más estructural como en la puramente territorial, siempre presentes como objetivos implícitos. Lo ligero en las estructuras y el ajuste con lo natural son probablemente las más mencionadas.

En el mundo de la ingeniería estructural, de los edificios y los puentes, la consecución de lo ligero siempre fue una meta de diseño. Construir más con menos, es un principio económico lógico, trascendido en dogma estético. Y para todos los constructores de puentes, la búsqueda de lo ligero ha sido una aproximación esencial al proceso de construir. De hecho, el nacimiento del hierro -tres veces más resistente que la piedra por unidad de peso- fue saludado como el gran acontecimiento estético del siglo XIX por Alfred G. Meyer en su famoso Eisenbauten de $1907^{13}$.

Con el hierro, el volumen pétreo tradicional del edificio se eleva para constituir la torre y se estira para formar la cubierta, dos nuevos tipos de construcciones protagonistas de la modernidad del cambio de siglo. Como señaló Walter Benjamin en sus Pasajes, con la ayuda del cristal el hierro encontró su papel constructivo en las cubiertas de grandes invernaderos y estaciones de ferrocarriil ${ }^{14}$. La posterior evolución de lo ligero se basó en el empleo de cables y de textiles, en total continuidad de la misma idea.

Para el arquitecto Buckminster Fuller bastaba saber cuanto pesa un edificio para conocer su sofisticación, afirmación a menudo reconducida hasta identificarla con su valor estético. Sin embargo, no se debe simplificar la ligereza como la simple búsqueda de reducción de peso. Hay otras muchas maneras de introducir la ligereza en el diseño de edificios y puentes, indica Gregg Lynn, como "la levitación, la flotación, y la suspensión, conseguidas cuando un cuerpo alcanza múltiples grados de estabilidad" ${ }^{\prime \prime}$. Eso da entrada a las nuevas formas complejas, surgidas en los comienzos del siglo XXI de la mano de grandes arquitectos e ingenieros internacionales, y a menudo señaladas como posmodernas por la mera incapacidad de entenderlas o clasificarlas.

Pero, frente a todo ello, es la escala quien empieza a imponer sus leyes sobre las consideraciones técnicas y funcionales. Primero altera la manera tradicional de diseñar, luego los recursos

\footnotetext{
${ }^{12}$ Adorno, 1970:189.

${ }^{13}$ Meyer, 1907:27 y ss.

${ }^{14}$ Benjamin, 1940:177.

15 Lynn, 1996.
} 

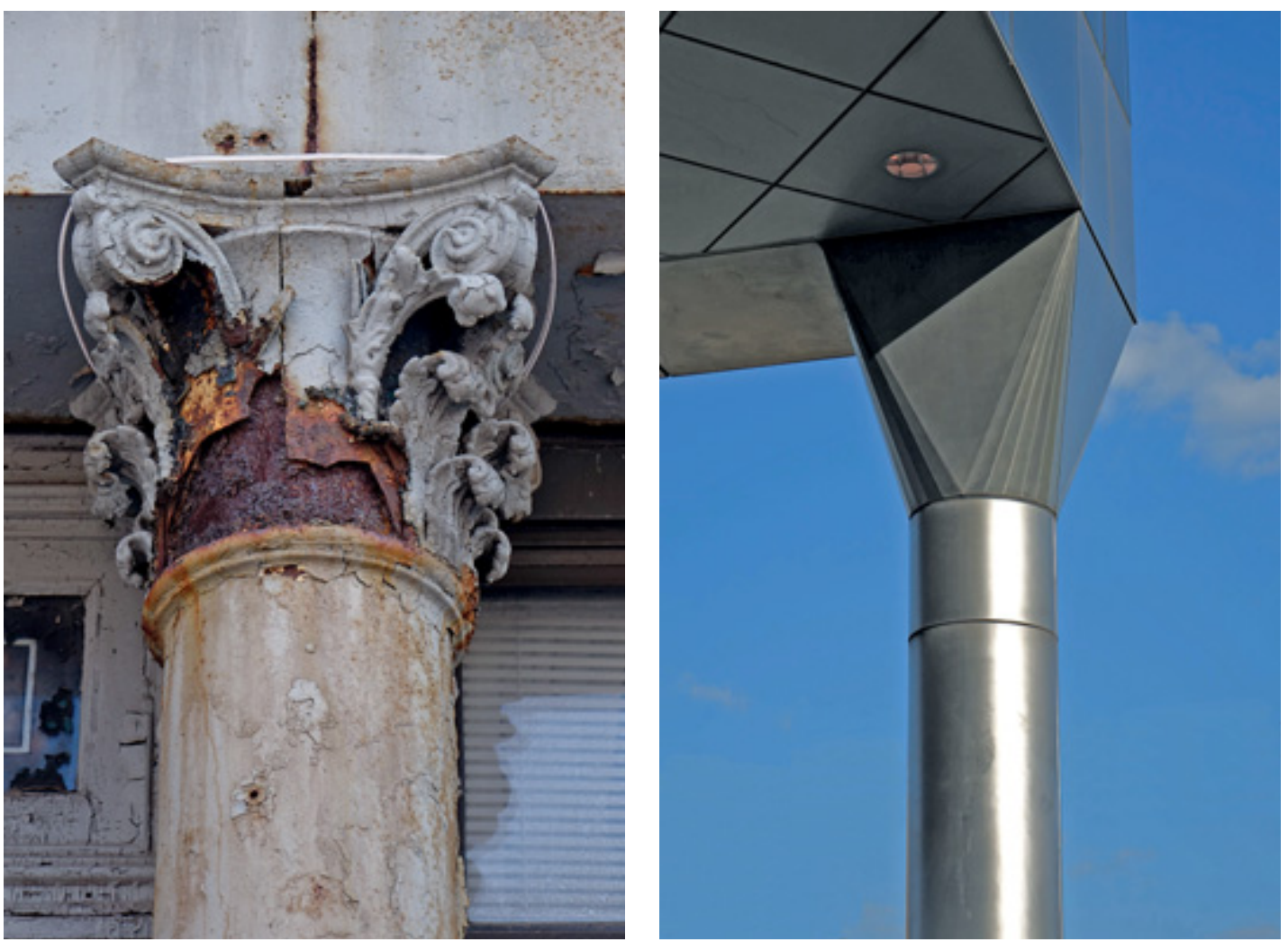

Figs. 4a y 4b. Capitel de hierro fundido en Hudson St y capitel de acero en Jamaica Station, Nueva York.

compositivos clásicos y, finalmente, se adueña del carácter de la obra para extenderse y abarcar cuanto nos rodea.

Algunos recursos compositivos clásicos se han revelado inapropiados a partir de ciertas escalas de actuación. El ornato, por ejemplo, tiene enormes dificultades de encaje en obras de cierta magnitud. Quizás por ello, muchos ingenieros han desarrollado una cierta alergia a su presencia. Entendido en la línea de pensamiento de Quatremère de Quency, como el empleo de los recursos de las Bellas Artes para resaltar el carácter de lo construido ${ }^{16}$, no logra aportar ninguna mejora perceptiva cuando la dimensión es importante. El valor de una cornisa en un pequeño puente de piedra se difumina hasta lo ridículo en un gran puente colgante.

Pese a ello, el ornato solo desaparece o es expulsado de lo construido cuando se produce un movimiento de renovación, cuando resulta útil renegar de lo anterior, de la carga histórica soldada a las formas técnicas. La arquitectura del movimiento moderno tomó ejemplo de las formas suaves y limpias de la ingeniería (del hormigón, nunca del acero) para abandonar el historicismo. Pero fue un asunto instrumental, para ayudarse en la negación de lo anterior, y pronto volvió a generar nuevos recursos ornamentales. Pues el ornato también se renueva y reaparece bajo diferentes ropajes, siempre ligados a lo particular del país y la época por la memoria histórica (figs. 4a y 4b).

\footnotetext{
${ }^{16}$ Quatremère, 1832:306.
}

Arch. esp. arte, LXXXIX, 354, ABRIL-JUNIO 2016, 165-182

ISSN: 0004-0428, eISSN: 1988-8511, doi: 10.3989/aearte.2016.11 
Al evitar cualquier distracción ornamental y circunscribir la expresión a la pura revelación de lo resistente, se negaba el papel creativo del diseño. Como afirmaba Condit: "La teoría de que las estructuras bien diseñadas personifican una geometría abstracta, que es la esencia de la belleza, es un sinsentido neoplatónico. La extensión de lo empírico en la forma estética por medio de las matemáticas es producto de una adolescente idolatría de la nueva tecnología" ${ }^{17}$.

Lo curioso es que todo ello ocurría en un período enormemente fructífero de obras de ingeniería creativas. En los 1920 y 1930, los ingenieros punteros, Maillart, Torroja, Freyssinet, Nervi y tantos otros, produjeron una serie de obras maestras como nunca en la historia.

\section{Problemas de escala: contexto y paisaje}

$\mathrm{Al}$ insertarse en el mundo, la acción del hombre queda impregnada de la magnitud de lo que confronta. En un primer momento, esto se interpretó en términos de conquista, como afirmación de una pretendida victoria del hombre en la confrontación con las leyes naturales. Eso no era sino una manifestación extrema del clásico dualismo hombre mundo, que Heidegger desmontó definitivamente al instaurar su ser-en-el-mundo. De esa nueva perspectiva surgió una diferente manera de entender esa relación hombre-mundo como manifestación de la propia vida, más cercana a la fenomenología.

En esas coordenadas, el contexto adquiere una importancia sustancial para la valoración de la obra del hombre. Las posibles 'virtudes' de ésta no nacen ya solamente de la propia obra sino de un sutil juego de relaciones con el particular mundo donde se inserta. Importa su manera de situarse en lo existente pues, al tomar cuerpo, la obra empieza a participar del mundo mismo y nunca lo podrá hacer aisladamente. Está obligada 'a vivir' en medio de otras cosas y deberá manifestar cómo aspira a relacionarse con ellas, tanto si pretende violentarlas como si aspira a una completa comunión o se conforma con una buena vecindad.

\section{Dimensión y escala}

El tamaño de lo construido ha sido utilizado en la historia como medio para producir impresión de seguridad o poder. Baste recordar las grandes catedrales o el propio San Pedro del Vaticano, expresamente dimensionado para abrumar a los visitantes con el poder de la Iglesia. Pues el tamaño de las cosas está ligado a nuestra capacidad de comprenderlas, de asumirlas, de sorprendernos o incluso de temerlas ${ }^{18}$.

Pero el aumento de la dimensión - materializado por la ingeniería de hoy- conlleva cambios obligados en nuestra percepción. Como dice Manterola, "El cambio de escala, de geometría y de la naturaleza del problema separa de tal manera la esencia de un arco de iglesia de la de un gran arco de puente, que parece que estuviéramos hablando de cosas distintas, como en realidad lo son" ${ }^{19}$.

Cuando la obra del hombre adquiere suficiente dimensión, su encaje en ese mundo donde aspira a vivir empieza a ser determinante de su conformación. Su propia configuración comienza a ser más deudora de cuanto hay en su derredor que de leyes o parámetros de composición dictados por teorías y prácticas anteriores, esto es, por la historia. "Para las nuevas formas inventadas, creadas y configuradas por el ingeniero, no existen ni pueden existir referencias", recuerda Manterola ${ }^{20}$.

\footnotetext{
${ }^{17}$ Condit, 1961:303.

${ }^{18}$ López Peláez, 1993:40

19 Manterola, 2007:33.

${ }^{20}$ Manterola, 2007:28.
} 


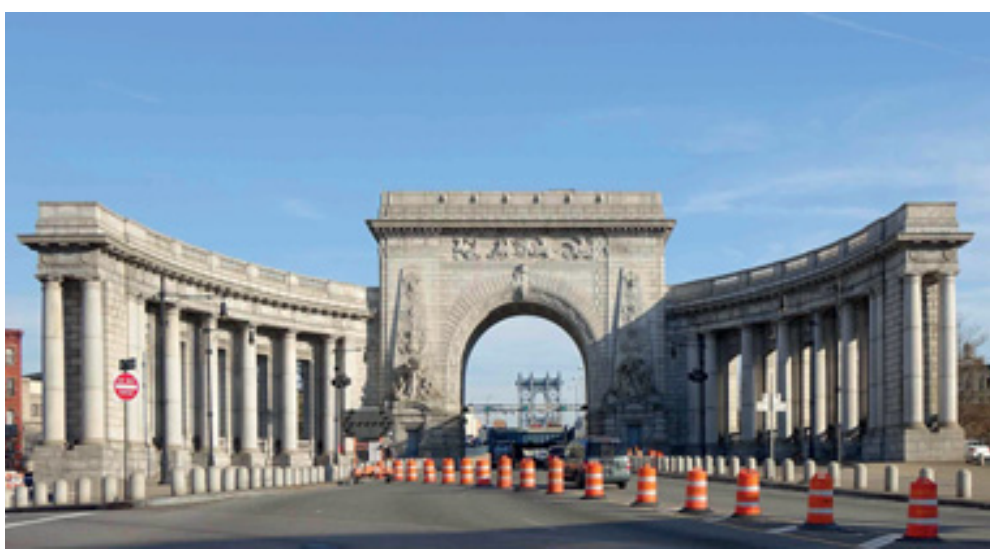

Fig. 5. Escala urbana del pórtico oeste de acceso al Puente de Manhattan.

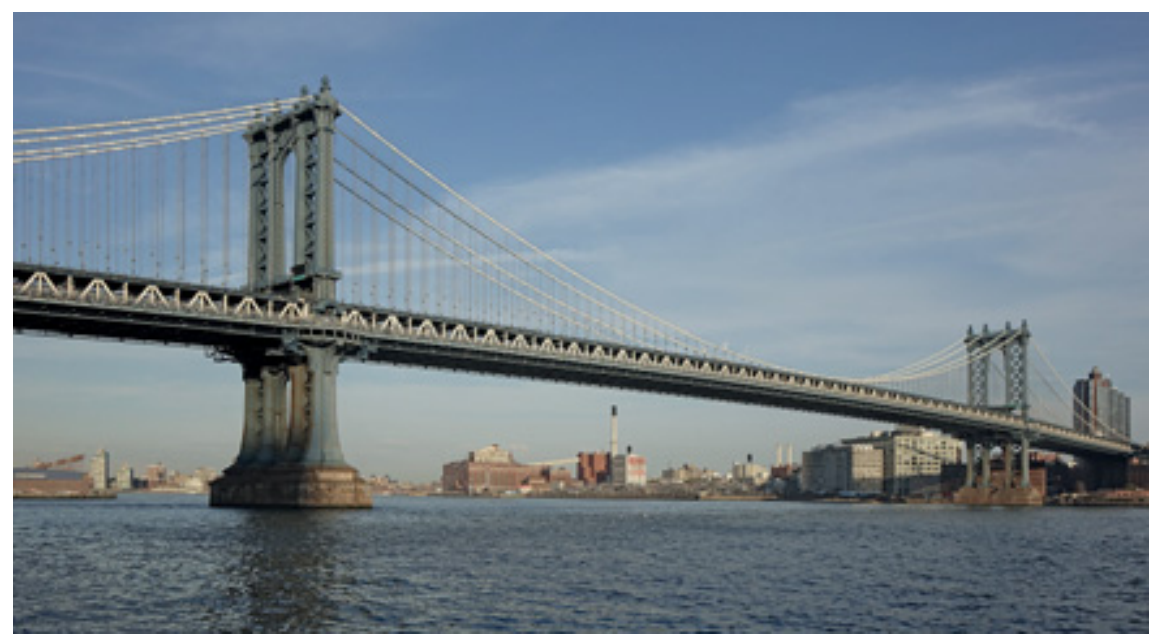

Fig. 6. Escala geográfica del Puente de Manhattan, de $2000 \mathrm{~m}$ de longitud y $450 \mathrm{~m}$ de vano (Modjeski \& Moisseiff, 1909).

Pero no se trata tanto de que esas pautas pierdan vigencia sino de que, frente a la novedad y desmesura de lo creado, parece obligada su interpretación con mayor apertura de miras. Es probable que muchos de los principios regidores de la estética sigan vigentes, pero su utilidad para guiar el diseño viene condicionada por su capacidad de adaptación a las dimensiones de cuanto de hace, a la escala utilizada para calibrarlo (figs. 5 y 6 ).

Aunque sus raíces sean profundas, la mayoría de esas pautas clásicas han surgido de una escala de actuación proporcionada a la figura humana. Sus principales determinaciones provienen de un sistema perceptivo fundamentalmente centrado en la capacidad sensorial del ser humano. Nuestra herencia cultural nos ha preparado para asumir con facilidad propiedades de los objetos o las obras como la simetría, el equilibrio o la proporción. Pero no estamos igualmente preparados para adjudicar categorías estéticas a lo que supera esa escala perceptiva.

Quizás por ello, se ha tratado de buscar otras fuentes de belleza en obras de grandes dimensiones capaces de impresionar, sin ningún margen de duda, a las sensibilidades más exquisitas. El descubrimiento de lo pintoresco por Uvedale Price en 1794 puede ser entendido como una posible fuente de valor para explicar ese atractivo.

Arch. esp. arte, LXXXIX, 354, ABRIL-JUNIO 2016, 165-182

ISSN: 0004-0428, eISSN: 1988-8511, doi: 10.3989/aearte.2016.11 


\section{Naturaleza y artificio}

Como no podía ser de otra manera, los ingenieros siempre han sido conscientes de la magnitud de la naturaleza confrontada con su quehacer. A finales del XIX la ingeniería sufrió un enorme cambio de escala, de la mano de los puentes colgantes de Roebling y posteriores. Su actitud frente a la naturaleza pasó entonces de los tintes épicos anteriores a marcar un carácter de 'conquista', mantenido hasta la generalización de un posterior 'respeto' bien entrada la segunda mitad del siglo XX.

En la consideración de lo natural, Fernández Casado mostraba una sensibilidad poco frecuente en los ingenieros de su época. Su vinculación familiar e identificación personal con la Institución Libre de Enseñanza están, probablemente, en la raíz de su manera de entender la relación del ingeniero con la naturaleza. El ingeniero tiene voluntad de 'economizar' precisamente 'por amor a la naturaleza': "las cosas y procesos del mundo físico desprenden resonancias en su interior y ponen en conmoción todas sus facultades: inteligencia sentiente, voluntad tendente y sentimiento afectante". Establece claramente la vinculación esencial de las obras de ingeniería a una naturaleza que "impone las dificultades a vencer". Y también señala la capacidad del paisaje para servir de archivo histórico pues "nos pone en comunidad con las obras de nuestros antecesores" 21.

Por su parte, Fernández Ordóñez daba un paso más para proponer una decidida "apropiación poética de la naturaleza". Su aproximación se orientaba más a nuestra capacidad de embellecer la naturaleza con nuestra actuación, en línea con el pensamiento clásico optimista sobre la acción del hombre. Son bien conocidas las sentencias de Aristóteles: "Perfeccionar la naturaleza es hacerla más útil para el hombre, más comprensible para su entendimiento, más bella para sus ojos". Platón: "No quiso Dios ver completo el mundo para que pudiese el hombre darle remate". Fichte: "La agricultura impondrá otro ritmo al aura morosa de los bosques primitivos"22.

Javier Manterola describe el modo en el que se da la relación del puente con su entorno, que se produce de una manera específica, y niega la posibilidad de objetivarla (fig. 7). Para él, "no existen soluciones a priori, tipos de puentes adecuados a tipos de paisaje, pero disponemos de respuestas ejemplares, de puentes que manifiestan la perfecta adecuación a un entorno"23.

En ayuda de estas posiciones, la consideración estética de la belleza natural ha sido puesta en cuestión, tanto por la actual debilidad de la propia idea de una naturaleza autónoma e intocada, como por la certidumbre de la ausencia de belleza en muchos paisajes naturales. Basta, quizás, con la tajante manifestación de Poe: "No podría encontrarse ni un lugar sobre la dilatada superficie de la tierra considerada en su estado natural, donde un ojo artístico que mire con fijeza no encuentre motivos de ofenderse". Eso viene apoyado por el convencimiento de que "La belleza original nunca es tan grande como la que se podría introducir"24.

Pues, de acuerdo con ello, los indudables excesos ingenieriles que afean el paisaje se producen no tanto por necesidad como por desidia. Considerada como ingrediente indispensable del diseño, la naturaleza es más bien una oportunidad y la obra puede contribuir a su mejora. Como afirma André Picon: "Para el ingeniero, la naturaleza no es destruida sino revelada por su trabajo. En lo más profundo, la naturaleza está muy próxima a al espíritu racional que actúa en su nombre. Sus principios responden a una geometría rigurosa, rigiendo tanto los impulsos del hombre como el comportamiento de la materia" 25 .

\footnotetext{
${ }^{21}$ Fernández Casado, 1976: 32 y 33.

${ }^{22}$ Una completa fundamentación de esta posición, de donde estan extraídas estas citas, se puede seguir en: Passmore, 1978.

${ }^{23}$ Manterola, 2008.

${ }^{24}$ Poe, 1842:108. Cit. en Barja, 2008:166.

${ }^{25}$ Picon, 1988:213
}

Arch. esp. arte, LXXXIX, 354, ABRIL-JUNIO 2016, 165-182 ISSN: 0004-0428, eISSN: 1988-8511, doi: 10.3989/aearte.2016.11 


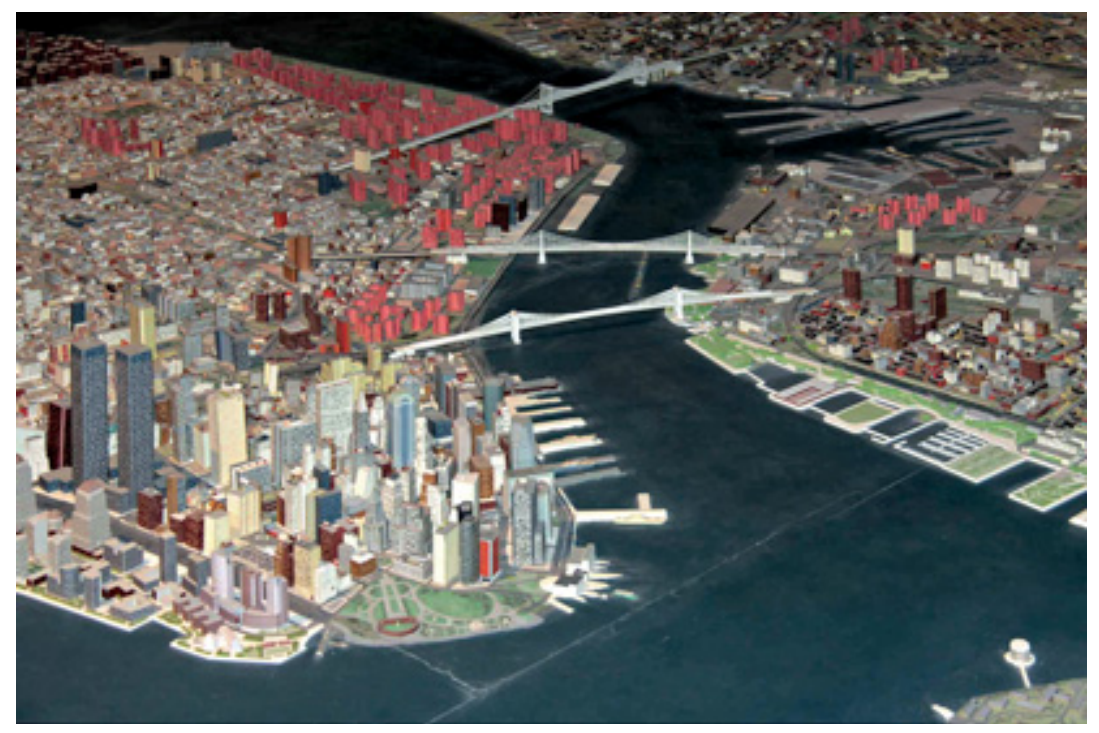

Fig. 7. New York City Panorama (Queens' Museum).

\section{La escasa aportación de lo sublime}

La dimensión de lo ingenieril y las dificultades de su construcción en una naturaleza poco propicia sino violenta han promovido cierta asociación de su estética con lo sublime, tal como fue conformado por Burke en su ensayo sobre lo sublime y lo pintoresco ${ }^{26}$. Para Picon,

la intuición de lo sublime se entrevé a partir de ciertos detalles del trabajo de los ingenieros. La expresión de los conflictos de estructura, lo desnudo de los paramentos, la búsqueda de contrastes violentos entre sombra y luz, por ejemplo, forman parte del vocabulario de Perronet. Generalmente, además, la construcción de estas obras toma a menudo un carácter heroico y sublime... en la medida en que se necesitan trabajos peligrosos que, de alguna manera, se termina por coronar ${ }^{27}$.

Pero lo sublime no se alcanza por las dimensiones, que solo llegan a lo grande, o mejor, a lo enorme, pues como dice el propio Burke, "un plan que no es grande más que por sus dimensiones, es claro indicio de una imaginación vulgar y encogida. Al tiempo, reclama que ninguna obra del arte es grande sino por lo que engaña; la verdadera grandeza es una prerrogativa de la naturaleza" ${ }^{28}$. Según ello, la grandeza de la obra vendría como apropiación del carácter de esa naturaleza a la que es capaz de vencer o como producto de esa difícil victoria, resumiendo una visión épica de la labor del ingeniero, típica de la segunda mitad del XIX.

Sin embargo, ya no resulta válido contemplar al ingeniero o, en general al ser humano que actúa en el mundo, como alguien ajeno a la naturaleza. Esa añeja contraposición filosófica del dualismo hombre naturaleza ha sido totalmente desmenuzada por la ciencia. Aunque el poder del ser humano es enorme y evidente, sabemos suficiente de su parentesco biológico con otras especies y de su vulnerabilidad frente a las consecuencias de sus propias actuaciones, como para considerarle parte indisoluble de esa naturaleza de la que gustaba distinguirse.

\footnotetext{
${ }^{26}$ Burke, 1987

${ }^{27}$ Picón, 1998:214

${ }^{28}$ Citado en Picón, 1988:214.
}

Arch. esp. arte, LXXXIX, 354, ABRIL-JUNIO 2016, 165-182

ISSN: 0004-0428, eISSN: 1988-8511, doi: 10.3989/aearte.2016.11 
Por otra parte, no cabe hablar de lucha cuando gran parte de lo que se actúa es rutina o simple desprecio. Las Obras Públicas podrán seguir siendo grandes logros, pero parece impropio hablar de batallas o de epopeyas para relatar su construcción. Con los conocimientos y los medios actuales solo habrá dificultades, éxitos o fracasos: ir más allá sería pura retórica. Aquel terror surgido de la soledad o la inmensidad, asociado por Burke a lo sublime y capaz de producir placer, no puede surgir de la mera dimensión de lo construido, cada vez más habitual y conspicuo ${ }^{29}$.

\section{Posibilidades de lo pintoresco}

Menos cuestionable -aunque ahora algo menospreciado- parece el concepto de lo pintoresco. Establecido por Uvedale Price en comparación con lo sublime y lo bello ${ }^{30}$, está basado en la coexistencia de lo natural y lo construido, con sus contrastes e irregularidades. Aquel primer carácter rústico, tan apropiado para las pinturas de paisajes del XVIII ha sido reformulado por artistas más recientes como Robert Smithson, Richard Long, James Fulton, David Nash o Walter de María, cuya obra es agrupada bajo la rúbrica de land art, para entender paisajes industriales devastados $\mathrm{y}$ considerarlos en términos estéticos en torno a ideas de cambio o secuencia temporal ${ }^{31}$.

En concreto, lo pintoresco ofrece la posibilidad de entender lo estético como secuencia temporal narrativa. Los objetos -antes aislados- se consideran dentro de un contexto y se perciben desde el movimiento, lo que se ajusta bien a las cualidades de la ingeniería. La Obra Pública es portadora de una geometría propia muy potente, cuya acordada inserción en el terreno propicia la posibilidad de una distancia estética que se puede entender cabalmente como pintoresca. Y las obras lineales como carreteras, ferrocarriles y canales muestran mejor que ninguna otra esas posibilidades estéticas, con matices particulares en cada caso.

Las curvas del ferrocarril tienen unos radios mínimos de centenares de metros y las pendientes son de pocos milímetros por metro, de manera que, en zonas abruptas, las vías se ven obligadas a separarse del terreno, penetrando en él por medio de túneles o sobrevolándolo con viaductos. Los trazados antiguos se adaptaban con muchas curvas, pequeños puentes y pocos túneles pero, con la alta velocidad, los radios se agrandan, los bucles son inviables, las alineaciones se rectifican y la longitud de túneles y viaductos aumenta.

La escasa pendiente de los canales marca el terreno como la materialización de una curva de nivel. A gran escala, el juego de alineaciones rectas y curvas de acuerdo revela las suaves ondulaciones del terreno y permite comprender sus flujos. De cerca, terraplenes y desmontes consiguen el ajuste fino de la plataforma con el microrelieve.

Las carreteras presentan una mayor flexibilidad para ajustarse al terreno pero la mayor anchura de su plataforma, especialmente en las autopistas, produce mayores dificultades. El sinuoso trazado de las pequeñas carreteras rurales supone una docilidad imposible en las autopistas donde grandes raspaduras de las laderas evidencian la presión ejercida sobre el territorio para encajarlas.

Estas obras de ingeniería nos son propias, forman parte y permiten comprender un paisaje que nos rodea y está impregnado de nuestro quehacer. No son pintorescas como analogía formal a aquellos elementos humanizados introducidos en la composición para dar interés al cuadro. Pero retienen algo de aquel carácter en cuanto nos son conocidas y habituales al señalar nuestro seren-el-mundo. Ya no hablan de lo rústico, sino de una conspicua tecnología a gran escala, ahora tan habitual y necesaria como lo fue aquello (figs. 8 a y 8 b).

\footnotetext{
${ }^{29}$ Burke, 1757.

${ }^{30}$ Price, 1794.

${ }^{31}$ Maderuelo, 1996:38.
}

Arch. esp. arte, LXXXIX, 354, ABRIL-JUNIO 2016, 165-182 ISSN: 0004-0428, eISSN: 1988-8511, doi: 10.3989/aearte.2016.11 

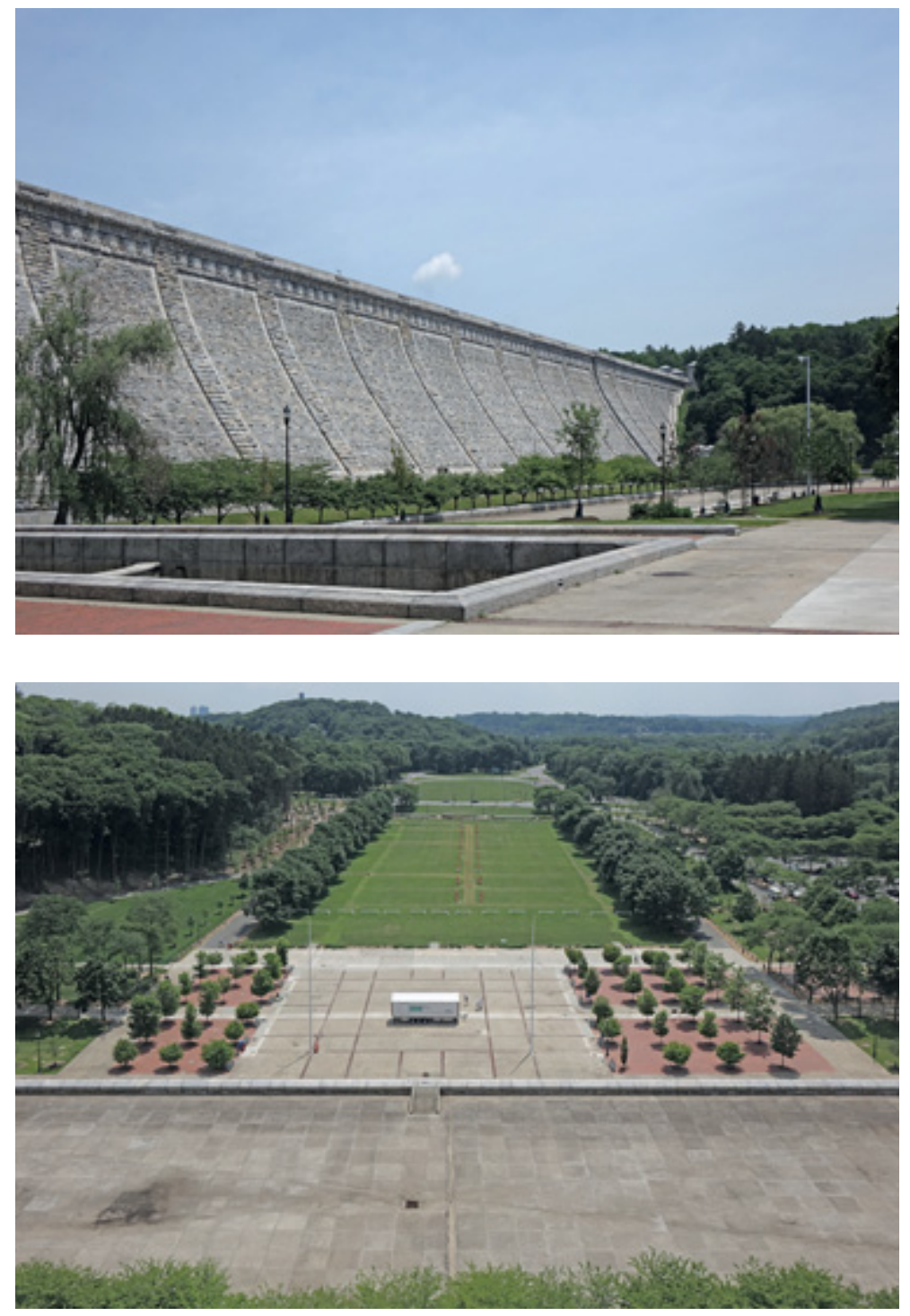

Figs. 8a y 8 b.

Presa de Kensico y explanada ajardinada aguas abajo (1884).

\section{Añadiendo significados: paisaje cultural e identidad}

En general, los artefactos que producimos y utilizamos tienen un doble papel. Sirven para propósitos físicos y conllevan mensajes de sus fabricantes o constructores. Sabemos leer esos mensajes y la información que contienen guía nuestros actos.

Los ingenieros se involucran activamente en las funciones y estudian cuidadosamente cómo crear formas, seleccionar materiales y establecer propiedades para satisfacerlas, mientras que los mensajes ligados e ellas son ignorados y sólo incidentalmente se convierten en cuestiones estéticas (fig. 9). Culturalmente, sin embargo, lo funcional se difumina o se da por descontado y el papel de los artefactos como signos, símbolos y emblemas es capaz de estructurarse en sistemas simbólicos más extensos o elaborados y se vuelve crucial. Los mensajes contenidos en lo construido

Arch. esp. arte, LXXXIX, 354, ABRIL-JUNIO 2016, 165-182

ISSN: 0004-0428, eISSN: 1988-8511, doi: 10.3989/aearte.2016.11 
suelen anunciar su uso o función, por semejanza con otros artefactos cuyas funciones son bien conocidas. Si se añade un campanario a un edificio se proclama como iglesia, aunque nunca vaya a albergar campanas ${ }^{32}$.

A menudo, los creadores tratan de generar asociaciones positivas para aumentar el deseo de poseer, utilizar, habitar o disfrutar lo construido. Para ello, utilizan recursos retóricos como la metonimia o la sinécdoque, de forma similar a cómo se hace en el discurso hablado o escrito. El uso de materiales nobles ayuda a que las obras se entiendan como monumentos, mientras que recursos compositivos como la simetría o el escalonamiento aportan clasicismo o recuerdan lo tradicional. De hecho, el empleo sistemático de alusiones y metáforas es uno de los recursos más utilizados en las construcciones más notables y creativas.

En los últimos veinte años se ha generalizado el empleo de la palabra infraestructuras para recoger el variado surtido de productos del construir. Antes se utilizaba el término Obras Públicas, con el énfasis claramente puesto en el destinatario de lo construido. Por el contrario, Infraestructura remite a la idea de subordinación, relega las obras en la jerarquía perceptiva de la importancia que damos a las cosas y las banaliza. Simplifica las obras públicas y las hace perder carga semántica, capacidad de evocación y presencia en los medios.

La consideración de las Obras Públicas como infraestructuras es meramente instrumental, se limita a resaltar su utilidad como apoyo a otras funciones o estructuras, consideradas más relevantes. Pero en el mundo donde vivimos siempre hay algo por encima o por abajo, todo puede ser infra o supra según quien lo mire. En el mundo de los ferrocarriles, por ejemplo, para quienes se ocupan de los trenes la infraestructura es la vía. Pero, para quienes cuidan la vía, la infraestructura es el terraplén y para quienes hacen terraplenes la infraestructura es el terreno y su preparación previa.

Sabemos que la ingeniería civil opera esencialmente en la esfera de lo público, donde se materializan las demandas y necesidades de la sociedad en obras concretas. Es por ello deseable llamarlas Obras Públicas pues, al ignorar ese carácter público y convertirlas en infraestructuras, se sustrae a ese público la posibilidad de participar y controlar la gestación de lo más propiamente suyo.

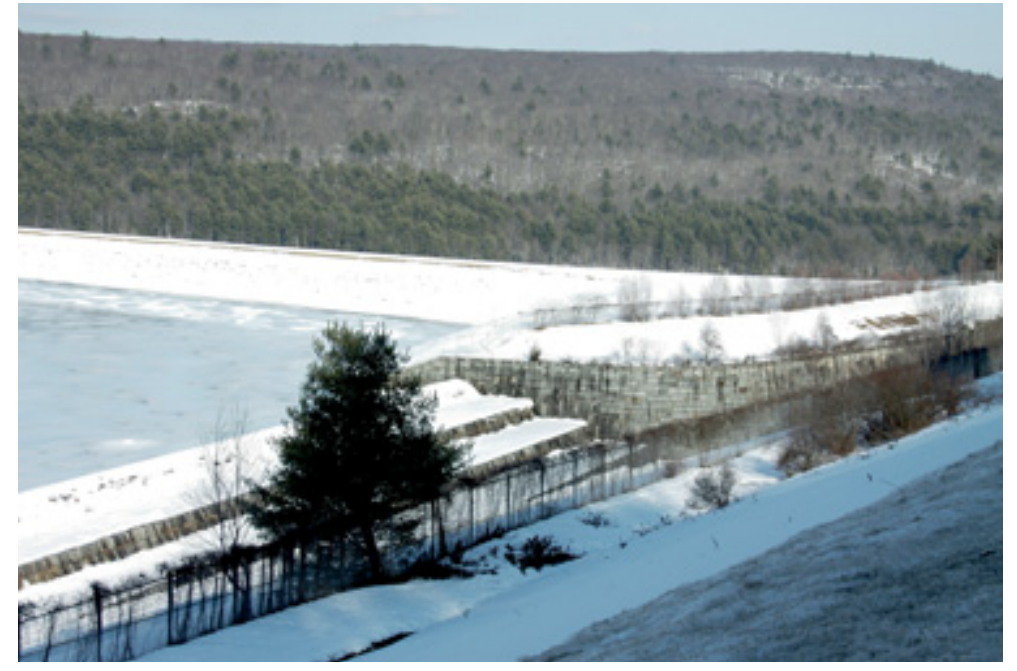

Fig. 9. Presa y embalse en Rondout Creek, del Sistema Delaware (1937-1964), para abastecimiento a Nueva York.

\footnotetext{
${ }^{32}$ Mitchell, 2008.
} 


\section{Como decía Rilke (1923) en sus Elegías a Duino:}

Camino, puente, dique, canal, embalse o puerto son hermosas y apropiadas palabras: no hay razón para dejar de usarlas. Aunque ya dijo el poeta, ¿Acaso estamos aquí para decir: casa, puente, fuente, puerta, jarra, árbol frutal, ventana; a lo más: columna, torre? Más que nunca van cayéndose las cosas, las que podemos vivir, pues lo que las sustituye, desplazándolas, es un hacer sin imagen.

Frente a esa pretendidamente inexorable pérdida semántica, lo que es esencial para el ser humano y potencialmente hermoso debe nominarse con bellas palabras. Pues, como afirma César Lanza, "Quitarle el nombre a cada obra es triturar su aura"33. En todo caso, no parece haber razón alguna para utilizar el término infraestructuras, que las devalúa y subordina a cualesquiera otras actuaciones posteriores.

En este sentido, Ángel Aparicio apunta la importancia de que los ciudadanos sientan como suyas las Obras Públicas desde la propia planificación y, más allá del autor, los considera como los verdaderos protagonistas:

El profesional debe abandonar la idea de adentrarse desde fuera en el carácter del lugar... La clave no reside en la genialidad del autor para diseñar esos nuevos espacios públicos de fortuna, sino en la legitimación de estos a través de su proceso participativo de diseño, con interacciones de todo tipo con ese residente o usuario convertido en fugaz protagonista. Es, en cualquier caso, la renuncia a lo sublime y la búsqueda pragmática de la belleza posible y del cambio incremental ${ }^{34}$.

Lo correcto de la propuesta participativa, sin embargo, no elimina el carácter de mediación de todo proceso de definición de la forma. Como afirma Heidegger, "el carácter de la obra reside en el hecho de haber sido creada por el propio artista" 35 . Serviría solamente como argumento para negar la procedencia de una reflexión estética, pero solo merecería consideración si esa reflexión abandonase la esencialidad del construir en el hombre. Y es ahí donde se pueden situar en una posición equilibrada todos los conceptos mencionados hasta ahora, tanto los intrínsecos a la propia obra, como los que incluyen el contexto.

\section{Hacia una estética del dónde}

La noción de construir como actividad esencial del hombre en el ejercicio de su habitar establecida por Heidegger ${ }^{36}$ ayuda a abandonar definitivamente el dualismo hombre-mundo. La vieja distinción aristotélica entre lo natural, aquello que tiene en sí mismo el principio de crecimiento, y lo artificial, aquello cuya constitución y movimiento son alterados violentamente por otro ser, pierde su sentido. El ser humano forma parte indisoluble del mundo alterado y es objeto -como todo lo demás- de las consecuencias de todo tipo derivadas de esa alteración. El distinguirse del resto añade escasa información para comprender sus actuaciones, con independencia de su condición de mediador.

Según afirma Félix Duque, si construir apunta en último término a la constitución misma del ser humano, "al menos para él existe una privilegiada región de lo ente a la que no cuadra esa disyunción exclusiva". En ella se ofrece al pensamiento una suerte de mediación entre lo natural y lo artificial, "un concepto intermedio que denota todas aquellas cosas que dejando espacio abierto a la existencia

\footnotetext{
${ }^{33}$ Lanza, 2011:13.

${ }^{34}$ Aparicio, 2013:48.

${ }^{35}$ Heidegger, 1935:49 (pág. 46 en la edición original).

${ }^{36}$ Heidegger, 1951:143.
}

Arch. esp. arte, LXXXIX, 354, ABRIL-JUNIO 2016, 165-182

ISSN: 0004-0428, eISSN: 1988-8511, doi: 10.3989/aearte.2016.11 
humana, a la vez otorgan estancia a los divinos y a los mortales, al cielo y a la propia tierra. Y sólo por ese ámbito de mediación puede hablarse ulteriormente de lo natural y lo artificial" ${ }^{137}$.

Según ello, no parece correcto entender al hombre como un agente externo que impacta sobre el mundo. Ni entender lo construido como simple alteración antrópica de la naturaleza. Como reconoce el Convenio Europeo del Paisaje ${ }^{38}$, ya no cabe entender el paisaje sin incluir la acción del hombre como elemento esencial de la transformación del mundo, tanto si el producto de su quehacer es acertado y beneficioso para ese mundo, como si es equivocado, destructivo o insostenible.

Por razones estéticas o históricas surgidas de la propia obra o por los acontecimientos de cualquier tipo allí ocurridos, las obras públicas adquieren fuertes significados que se sueldan a ellas para producir lugares. Estos lugares provocan potentes sentimientos de pertenencia: la gente los entiende como suyos y reconocen las obras como señas de su propia identidad. Los paisajes culturales creados por los caminos, puentes, presas, canales o puertos pasan a formar parte de sus vivencias y recuerdos. Esos productos del construir son un componente primario, conspicuo e importante del conjunto de rasgos que diferencian su propia vida de las de los demás (figs. 10 y 11).

A menudo, ese protagonismo identitario no es percibido o reconocido por la misma gente que luego protesta si se esas obras se alteran o eliminan. Su propia utilidad oculta o vela el carácter esencial de su presencia. El sencillo experimento de borrar con un programa de retoque la presencia del puente o el camino en una fotografía, basta para desvelar su protagonismo. Los mismos paisajes sin las obras construidas dejan de ser conocidos, dejemos de pertenecer a esos lugares porque son simples extensiones de terreno sin rasgos distintivos. Recordando a Heidegger, sin el puente que construye el lugar, el sitio no es más que un tramo de río indiferenciado.

Con el actual control digital de la técnica y la progresiva independencia de los modelos y sugerencias formales contenidos en los tipos, el anclaje funcionalista de la estética ingenieril tradicional deja de ser un requisito. Además, el propio devenir de las condiciones de vida ha demostrado con creces que la función se vuelve obsoleta más rápidamente que lo construido. El clásico principio de "La forma sigue a la función" enunciado por Louis Sullivan, se ha dado la vuelta. Ahora buscamos cómo utilizar magníficos edificios que se han quedado sin función. Eso reconduce el problema, pues el abrazo de la funcionalidad llevaba la cuestión de la estética de la ingeniería a un callejón sin salida.

Con todo ello, la mirada crítica se ha de volver al 'topos' como principal inspirador de una estética de la ingeniería, ya escasamente anclada en la funcionalidad o en la técnica y carente de modelos históricos en virtud del imparable crecimiento de sus dimensiones. Ello no supone, realmente ninguna novedad estética. El propio Heidegger "encuentra el ser de la obra en la confrontación del mundo con la tierra" 39 , del hombre y su carga histórica con su soporte vital. Todo el problema nace de la especial relación del hombre con su mundo. Y todos los conceptos espaciales de medida, dirección, orientación, cercanía, paraje, sitio, etc. derivan de la consideración de ese mundo como el mundo circundante del ser y se prologan en su concepto del ser-ahí.

“Todos los 'dónde' son descubiertos e interpretados por el 'ver en torno' a través de las vías y caminos del cotidiano 'andar en torno', no señalados ni fijados midiendo 'teóricamente' el espacio" 40 . Esa relativización del espacio da entrada directa a una diferente manera de entender el espacio según la evolución del hombre y sus necesidades-posibilidades en cada época. La escala se superpone a la dimensión en cuanto supera la medición por la vivencia y es más útil para entender nuestra actual relación con el mundo.

\footnotetext{
${ }^{37}$ Duque, 2008:145.

${ }^{38}$ Consejo de Europa, 2000

${ }^{39}$ Heidegger, 1935:41 (pág. 38 en la edición original).

${ }^{40}$ Heidegger, 1927:118.
} 


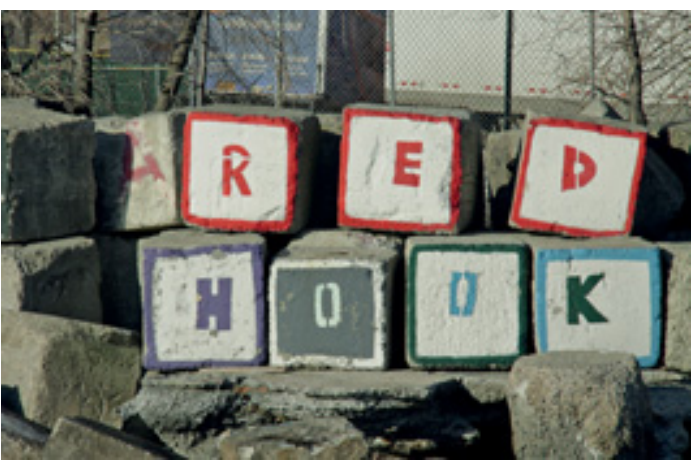

Fig. 10. Trivialización del nombre del antiguo puerto de Brooklyn sobre los bloques del dique.

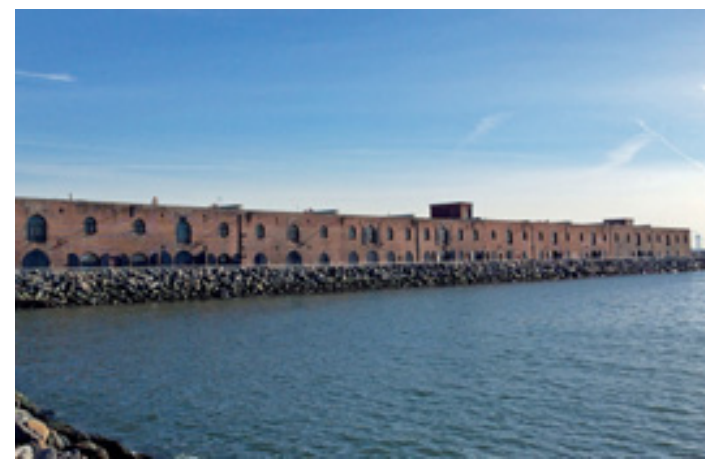

Fig. 11. Almacenes portuarios en Red Hook (Brooklyn), reconvertidos en talleres de artistas en 2013.

Por ejemplo, las diferencias entre los puentes de Alcántara y Mérida se explican mejor por el dónde que por el tipo, la época o el material. Ambos están constituidos por arcos y en ambos casos son arcos romanos y de piedra. Sus dimensiones y número de vanos son muy diferentes, pero la razón de ello no es histórica ni estilística. Sus diferencias surgen del muy distinto carácter del cauce y del régimen hidráulico de los ríos salvados, en definitiva, de los problemas creados en función del 'dónde' se ubican. El puente de Alcántara - de carácter unitario, alto y poderoso- está encajado en un valle del Tajo de laderas muy pendientes y el río desagua una gran cuenca hidrográfica con frecuentes crecidas. El puente de Mérida -largo y con muchos vanos añadidos en distintas épocas- salva el Guadiana en un lugar plano, con una isla y un vado, causa de su elección para construir allí la ciudad. En Alcántara las crecidas del río aumentaban su nivel y su fuerza era confrontada por lo robusto de la fábrica. En Mérida el río se desbordaba suavemente y las crecidas se combatieron añadiendo nuevos tramos.

Esta clara dependencia de las obras respecto a los sitios no se debe entender como una pertenencia. El sitio "no debe interpretarse como el 'donde' de las cosas", sino en relación con su conformidad respecto al 'todo de útiles' que 'están a la mano' del 'ser-en-el-mundo' ${ }^{41}$. La conexión de la obra con el sitio pasa por responder a una necesidad (ser útil) del ser humano, activada en un momento dado dentro del ámbito donde se habita.

Según ello, el dónde es elemento indispensable para comprender la obra pero, al igual que la dimensión se debe mediatizar como escala, debe incluirse no como una propiedad espacial autónoma, sino en relación con el sujeto principal del construir. Por encima de la idea espacial de $u b i$ cación debe incluir su capacidad de expresar movimiento y orientación, debe entenderse -fenomenológicamente y en su sentido más próximo al ser humano- como parte de su habitar ${ }^{42}$.

Entonces, la técnica, la funcionalidad, la escala o el contexto vuelven a adquirir sentido como elementos a tener en cuenta para determinar el interés de la obra. Pero deben considerarse conjunta y relativamente para entender la aportación del creador, en un momento histórico concreto, a una configuración formal que siempre será el objeto principal de cualquier valoración artística.

\footnotetext{
${ }^{41}$ Heidegger, 1927:118

${ }^{42}$ Cassey, 1997:231.
}

Arch. esp. arte, LXXXIX, 354, ABRIL-JUNIO 2016, 165-182

ISSN: 0004-0428, eISSN: 1988-8511, doi: 10.3989/aearte.2016.11 


\section{BIBLIOGRAFÍA}

Adorno, Theodor W. (1970): Teoría estética. Barcelona: Orbis, 1983.

Aguiló, Miguel (2002): "Invariantes estéticos de la ingeniería civil”. En: Revista de Obras Públicas, 3426, Madrid, pp. 59-68.

Aguiló, Miguel (2008): Forma y tipo en el arte de construir puentes. Madrid: Abada.

Aguiló, Miguel (2013): Qué significa construir. Claves conceptuales de la Ingeniería Civil. Madrid: Abada.

Aguiló, Miguel (2014): "Las Obras Hidráulicas como patrimonio territorial”. En: Las Obras Hidráulicas de la Ilustración, Catálogo de la exposición, CEDEX, Madrid, pp. 19-27.

Aparicio Moruelo, Ángel (2013): "Estética y fines en la obra pública”. En: Revista de Obras Públicas, 3544, Madrid, pp. 45-50.

Argan, Giulio Carlo (1966): Enciclopedia Universale dell'Arte. Florencia: Sansoni.

Barja, Juan (2008): Ausencia y Forma. Madrid: Abada.

Benjamin, Walter (1982): Das Passagen-Werk. Suhrkemp. Fráncfort: Fráncfort del Meno. [Ed. Esp. (2005): Libro de los pasajes. Madrid: Akal].

Burke, Edmund (1757): Indagación filosófica sobre el origen de nuestras ideas acerca de lo sublime y lo bello. Madrid: Tecnos, 1987.

Cassey, Edward S. (1997): The fate of place. A philosophical history. Berkeley: University of California Press.

Condit, Carl W. (1961): American building art: The twentieth century. New York: Oxford University Press.

Consejo de Europa (2000): Convenio Europeo del Paisaje. Madrid: Ministerio de Asuntos Exteriores.

Duque, Félix (2008): Habitar la tierra. Medio ambiente, Humanismo, Ciudad. Madrid: Abada.

Fernández Casado, Carlos (1976): Estética de las artes del ingeniero. Madrid: Real Academia de Bellas Artes de San Fernando.

Fernández Ordóñez, José A. (1990): El pensamiento estético de los ingenieros. Funcionalidad y Belleza. Madrid: Real Academia de Bellas Artes de San Fernando.

Heidegger, Martin (1927): El ser y el tiempo. México: Fondo de Cultura Económica, 2008.

Heidegger, Martin (1935): "El origen de la obra de arte". En: Caminos del bosque. Madrid: Alianza, 1995.

Heidegger, Marti; (1951): “Construir, habitar, pensar". En: Conferencias y artículos. Barcelona: Serbal, 1994.

Lanza, César (2011): Seis ingenieros vivos. Ensayos en torno al pensamiento y la obra de Miguel Aguiló, Javier RuiWamba, José Luis Manzanares, Luis Irastorza, Eugenio Oñate y Alfredo Irisarri. Madrid: Aula Carlos Roa- INECO.

López Peláez, José Manuel (1997): "La humanidad en peligro. Una reflexión sobre la escala". En: Circo, 40, Madrid.

Lynn, Gregg (1996): “Levedad”. En: Circo, 34, Madrid.

Maderuelo, Javier (1996): Nuevas visiones de lo pintoresco: el paisaje como arte. Lanzarote: Fundación César Manrique.

Manterola Armisén, Javier (2007): "Relación entre la estructura resistente y la forma. Notas en torno a la valoración estética de los puentes". En: Revista de Obras Públicas, 3.476, Madrid, pp. 23-40.

Manterola, Javier (2008): "Estética del puente". En: Pérez Carreño, Francisca (eds.) (2008): De la naturaleza salvaje al patrimonio cultural: un enfoque estético. Madrid: CEHOPU.

Meyer, Alfred Gotthold (1907): Eisenbauten: ihre geschichte und Aestheti. Berlín: von. Paul Neff Verlag. Ed. Fra. (2005): Construire en fer. Histoire et esthétique. París: Gollion,

Mitchell, William J. (2008): World's Greatest Architect. Making, Meaning, and Network Culture. Massachusetts: MIT Press.

Passmore, John (1978): Man's responsibility for nature - Ecological problems and western traditions. Gerald Duckworth. Ed. esp. (1990): La responsabilidad del hombre frente a la naturaleza. Madrid: Alianza.

Picon, Antoine (1988): Architecte et Ingénieurs au siècle des lumières. Marsella: Parenthèses. 2004.

Poe, Edgar Allan (1842): "The Domain of Arnhem or the Landscape Garden". En: The complete illustrated Stories and Poems. Londres: Chancellor Press, 1994.

Price, Uvedale (1794): An essay on the Picturesque, as Compared with the Sublime and the Beautiful. Londres : J. Robson. Quatremère de Quincy, Antoine (1832): Dictionnaire historique d'architecture. París: Librairie d'Adrien le Clères.

Schopenhauer, A. (1819): Le monde comme volonté et comme représentation. París: Presses Universitaires de France, 1978.

Fecha de recepción: 05-IX-2014

Fecha de aceptación: 03-XI-2014

Arch. esp. arte, LXXXIX, 354, ABRIL-JUNIO 2016, 165-182 ISSN: 0004-0428, eISSN: 1988-8511, doi: 10.3989/aearte.2016.11 